\title{
Qualidade da educação superior e a responsabilidade social
}

\section{Quality of higher education and social responsibility}

\section{Calidad de la educación superior y la responsabilidad social}

\author{
Jardelino Menegat ${ }^{1}$ \\ Universidade Católica de Petrópolis, Reitor e Professor do Programa de Pós-graduação em \\ Educação

\section{Ricardo Antônio De Marco²} \\ Universidade do Oeste de Santa Catarina de Chapecó, Vice-reitor

\begin{abstract}
Dirléia Fanfa Sarmento ${ }^{3}$
Universidade La Salle, Professora no Curso de Pedagogia e do Programa de Pós-graduação em Educação
\end{abstract}

Resumo: As reflexões ora apresentadas são decorrentes de uma pesquisa teórica em andamento, cuja temática focaliza a educação de qualidade vista sob a perspectiva dos seus fundamentos e modos de efetivação nos contextos educacionais. Faz um recorte sobre a qualidade da Educação Superior, avaliada por meio do Sistema Nacional de Avaliação da Educação Superior (SINAES), refletindo sobre a Responsabilidade Social enquanto uma das 10 dimensões analisadas nesse Sistema. Com base na revisão de literatura, os achados do estudo sinalizam para a Responsabilidade Social como um componente essencial no processo formativo dos acadêmicos, para o cumprimento da tríplice missão universitária do ensino, da pesquisa e da extensão e para a efetivação da própria função social das Instituições de Ensino Superior.

Palavras-chave: Qualidade da educação. Educação superior. SINAES. Responsabilidade social.

\footnotetext{
1 Pós-Doutor em Educação pela Universidade Federal Fluminense; Doutor em Educação pela Universidade La Salle.

2 Mestre em Administração pela Universidade do Sul de Santa Catarina; doutorando no Programa de Pós-graduação em Educação da Universidade La Salle.

3 Pós-Doutora em Ciências da Educação pela Universidade do Algarve (Portugal); Pós-Doutora em Educação pela Universidade Federal Fluminense.
} 
Abstract: The reflections presented here derive from a theoretical research in progress, whose theme focuses on quality education seen from the perspective of its foundations and modes of effectiveness in educational contexts. It makes a clipping about quality of Higher Education, evaluated through the National System of Evaluation of Higher Education (SINAES), reflecting about Social Responsibility as one of the ten dimensions analyzed in this System. Based on the literature review, the study findings point to Social Responsibility as an essential component in the academic training process; to fulfill the threefold university mission of teaching, research and extension; And for the realization of the social function of Higher Education Institutions.

Keywords: Educational Quality. Higher education. SINAES. Social Responsability.

Resumen: Las reflexiones que ahora son presentadas son derivadas de una investigación teórica en curso, cuya temática se enfoca en una educación de calidad mirada bajo la perspectiva de sus fundamentos y modos de hacerla efectiva en contextos educacionales. Hace un estudio exhaustivo sobre la calidad de la Educación Superior, evaluada por medio del Sistema Nacional de Evaluación de la Educación Superior (SINAES), reflexionando sobre la Responsabilidad Social en cuanto una de las diez dimensiones analizadas en este Sistema. Con base en la revisión de la literatura realizada, los descubrimientos del estudio señalan a la Responsabilidad Social como un componente esencial en el proceso formativo de los académicos; para el cumplimiento de la triple misión universitaria de enseñanza, investigación y extensión; y para hacerla efectiva de la propia función social de las Instituciones de Enseñanza Superior. Palabras clave: Calidad de la Educación. Educación Superior. SINAES. Responsabilidad Social.

\section{INTRODUÇÃO}

O direito à educação tem sido firmado em vários dispositivos legais no cenário brasileiro, os quais estão em consonância com a discussão mundial acerca de tal tema. A Declaração Universal dos Direitos Humanos (ORGANIZAÇÃO DAS NAÇÕES UNIDAS, 1948), ao firmar o direito à educação como um dos direitos a ser assegurado a todas as pessoas ao lado dos demais direitos, tornou-se um marco referencial para o surgimento de outros dispositivos, cujo cerne está fundamentado no que preconiza essa Declaração. Articulado ao direito à educação, emerge no debate mundial a questão 
da qualidade educacional desde a Educação Básica até a Educação Superior e, em decorrência, a necessidade de sistemas e modos de avaliação dessa qualidade.

No Brasil, uma das formas instituídas para avaliar a qualidade educacional nas IES é o Sistema Nacional de Avaliação da Educação Superior (SINAES), instituído pela Lei n. 10.861, de 14 de abril de 2004. Esse Sistema tem a "missão de avaliar a graduação, valorizando aspectos indutores da melhoria da qualidade da Educação Superior e da formação acadêmica dos estudantes brasileiros.” (BRASIL, 2004). O objetivo do SINAES é "assegurar processo nacional de avaliação das instituições de educação superior, dos cursos de graduação e do desempenho acadêmico de seus estudantes." (Art. $\left.1^{\circ}\right)$ (BRASIL, 2004). O Sistema tem como finalidade

[...] a melhoria da qualidade da educação superior, a orientação da expansão da sua oferta, o aumento permanente da sua eficácia institucional e efetividade acadêmica e social e, especialmente, a promoção do aprofundamento dos compromissos e responsabilidades sociais das instituições de educação superior, por meio da valorização de sua missão pública, da promoção dos valores democráticos, do respeito à diferença e à diversidade, da afirmação da autonomia e da identidade institucional. (BRASIL, 2004, $\S 1^{\circ}$ ).

A estrutura avaliativa do Sistema contempla a avaliação de três componentes: das Instituições de Ensino Superior (a autoavaliação e a avaliação externa), a avaliação dos cursos de graduação (organização didático-pedagógica, o perfil do corpo docente e as instalações físicas) e a dos estudantes (Exame Nacional de Desempenho de Estudantes - ENADE). Também complementam o SINAES os seguintes instrumentos de informação: o Censo da Educação Superior e o Cadastro de Cursos e Instituições (BRASIL, 2014).

Segundo a Nota Técnica n. 14/2014 (BRASIL, 2014), o conjunto de dimensões avaliativas do referido Sistema está organizado em cinco eixos, com suas respectivas dimensões de avaliação, a saber:

a) Eixo 1: Planejamento e Avaliação Institucional (Dimensão 8: Planejamento e Avaliação);

b) Eixo 2: Desenvolvimento Institucional (Dimensão 1: Missão e Plano de Desenvolvimento Institucional; Dimensão 3: Responsabilidade Social da Instituição); 
c) Eixo 3: Políticas Acadêmicas (Dimensão 2: Políticas para o Ensino, a Pesquisa e a Extensão; Dimensão 4: Comunicação com a Sociedade; Dimensão 9: Política de Atendimento aos Discentes);

d) Eixo 4: Políticas de Gestão (Dimensão 5: Políticas de Pessoal; Dimensão 6: Organização e Gestão da Instituição; Dimensão 10: Sustentabilidade Financeira);

e) Eixo 5: Infraestrutura Física (Dimensão 7: Infraestrutura Física).

Nesse texto, nosso interesse recai sobre o Eixo 2 e, mais precisamente, a Dimensão que focaliza a Responsabilidade Social (RS). A consideração da RS como um dos indicadores de qualidade educacional requer a discussão sobre tal conceito, tendo em vista que ele não pode ser compreendido como sinônimo ou expressão da filantropia, do voluntariado e/ou de ações de cunho assistencial, tampouco ser confundido com a extensão universitária, podendo ser ela uma das formas, dentre outras, a materializar a RS das instituições. É muito mais que isso, pois diz respeito à própria função social das Instituições de Ensino Superior e ao comprometimento delas com a formação de pessoas que possam contribuir para a transformação das estruturas sócio-históricas, políticas e econômicas que inviabilizam o respeito e a materialização do princípio da dignidade humana.

Igualmente, é fundamental a discussão sobre o que se compreende por qualidade da educação, pois se trata de um conceito polissêmico e passível de muitas conotações, considerando-se que está situado numa dimensão histórica que se modifica no tempo e espaço conforme as demandas sociocontextuais (DOURADO; OLIVEIRA, 2009). Portanto, mais do que a busca por uma única definição, em razão da sua complexidade e abrangência (DOURADO; OLIVEIRA; SANTOS, 2007), é necessário contemplar as múltiplas dimensões envolvidas em tal conceito (TAWIL; AKKARI; MACEDO, 2012), situando-o num contexto educacional, político, econômico e social mais amplo. Dessa forma, conforme destacam Dourado, Oliveira e Santos (2007, p. 7):

A análise da qualidade da educação deve se dar em uma perspectiva polissêmica, uma vez que essa categoria traz implícitas múltiplas significações. O exame da realidade educacional, sobretudo em vários países da Cúpula das Américas, com seus diferentes atores individuais e institucionais, evidencia que são diversos os elementos para qualificar, avaliar e precisar a natureza, as propriedades e os atributos desejáveis ao proces- 
so educativo, tendo em vista a produção, organização, gestão e disseminação de saberes e conhecimentos fundamentais ao exercício da cidadania.

Entretanto, não sendo o nosso objetivo neste texto entravar tal debate, limitamo-nos a abordar a avaliação da qualidade da educação no contexto do SINAES. Nesse sentido, as reflexões ora apresentadas são decorrentes de uma pesquisa teórica em andamento, cuja temática investigativa focaliza a educação de qualidade vista sob a perspectiva dos seus fundamentos e modos de efetivação nos contextos educacionais. Apresenta dados oriundos da revisão de literatura (livros, coletâneas e artigos) relativa à Responsabilidade Social e à Responsabilidade Social nas Instituições de Ensino Superior (ou Universitária). De acordo com Roesch (2010, p. 105):

A revisão de literatura permite, entre outros propósitos, levantar soluções alternativas para tratar de uma problemática. Por exemplo, levantar dados e informações contextuais para dimensionar e qualificar a problemática em estudo; levantar métodos e instrumentos alternativos de análise e assegurar ao seu autor que seu trabalho tenha alguma originalidade.

Feitas tais considerações, na próxima seção contextualizamos a evolução e respectivos enfoques da Responsabilidade Social nas organizações. Ressaltamos que, apesar de as Instituições de Ensino Superior constituírem uma tipologia organizacional, as discussões acerca desse tema nessas organizações surgem mais tardiamente, sendo o principal marco mobilizador a instituição do SINAES.

\section{RESPONSABILIDADE SOCIAL NAS ORGANIZAÇÕES: UMA VISÃO PANORÂMICA}

A reflexão mais efusiva sobre a Responsabilidade Social (RS), oriunda do contexto corporativo, remonta a década de 1950, nos Estados Unidos e na Europa, quando começam a se evidenciar os efeitos socioambientais do liberalismo econômico. Nessa década, a ênfase é no cunho econômico, sendo a RS "entendida como a capacidade empresarial de geração de lucros, criação de empregos, pagamento de impostos e cumprimento das obrigações legais." (TENÓRIO et al., 2006, p. 18). Gradativamente, começa a emergir a crítica à ênfase exacerbada no desenvolvimento econômico como alavanca do progresso, desconsiderando-se os impactos socioambientais, fruto de tal visão. De acordo com Daher (2006, p. 94): 
O conceito de responsabilidade social empresarial vincula-se ao reconhecimento de que as tomadas de decisão e os resultados obtidos com suas atividades atingem um universo de agentes sociais muito mais vasto do que o expresso por sócios e acionistas, porquanto muitas das decisões e atividades dos negócios trazem consequências para a comunidade, para o meio ambiente e outros interesses da sociedade. O pressuposto básico da responsabilidade social é o de que qualquer relação que a empresa mantenha com qualquer grupo terá essa dinâmica, como no caso ambiental, social, político, econômico e legal.

Nas décadas de 1960 e 1970 prossegue o aprofundamento sobre as questões éticas e sociais das empresas, colocando-se o acento nas repercussões do capitalismo exacerbado e seus efeitos para a sociedade. Diante do "esgotamento do modelo industrial e o desenvolvimento da sociedade pós-industrial, o conceito evoluiu, passando a incorporar os anseios dos agentes sociais no plano de negócios das corporações.” (TENÓRIO et al., 2006, p. 13). A Responsabilidade Social, segundo Daher (2006, p. 23),

[.... dobra-se às múltiplas exigências que a nova sociedade impõe, nas relações de parceria entre clientes e fornecedores, na produção de qualidade, com plena satisfação dos usuários, mediante transparência na mobilização das ações e contribuições para o desenvolvimento da comunidade, nos investimentos para o desenvolvimento da pesquisa tecnológica, na preservação do meio ambiente, pela intervenção de ações não predatórias, na participação dos trabalhadores nos resultados e decisões tomadas pelas empresas, no investimento e qualificação profissional, garantindo assim o respeito ao direito do cidadão etc.

Nessa perspectiva, a Responsabilidade Social leva em seu cerne a relação das organizações com o seu ambiente interno e externo, priorizando-se nessa relação a postura ética e a transparência nas ações. Na década de 1980, conforme Tenório et al. (2006, p. 24):

[...] com a retomada da ideologia liberal e com a globalização, o conceito de responsabilidade social empresarial sofre transformações, revestindo-se de argumentos a favor do mercado [...] Nessa acepção do conceito, o mercado é o principal responsável pela regulação e fiscalização das atividades empresariais, impedindo abusos por parte das companhias. Cabe ao consumidor retaliar por meio do boicote ou de protestos os produtos das empresas que não respeitam os direitos dos agentes e que poluam o meio ambiente.

Ainda, de acordo com Amorim (2009, p. 130): 
Desde o final da década de 80 a ética e a responsabilidade social passaram a ser temas importantes para a Administração e a Gestão Organizacional. Não é mais suficiente apenas produzir bens e serviços que sejam consumidos. É preciso ter eficácia organizacional e uma relação saudável com o meio em que se está inserido. É preciso, também, ter equilíbrio entre os interesses dos acionistas e agir com responsabilidade social em relação a toda a comunidade.

Assim, a ideia de desenvolvimento sustentável ganha força em vários movimentos, sendo firmada de forma mais efusiva a partir da década de 1990,

[...] como referente de la acción politica y social, como objeto de estudio de académicos e investigadores de diferentes áreas del conocimiento, como preocupación central de organismos multilaterales del tenor, por ejemplo, de la Organización de las Naciones Unidas, y como un llamado angustiante a la imposibilidad de pensar y hablar de desarrollo, si este concepto compromete la posibilidad de existencia de las próximas generaciones, la destrucción del medio ambiente, la exclusión social, el irrespeto de la dignidad humana, el desprecio por la vida en todas sus formas y manifestaciones, además del aumento exponencial de la pobreza. (GÓMEZ RESTREPO, 2010, p. 16).

No Brasil, a mobilização e os esforços denunciando a fome e a miséria, juntamente com a fundação do Instituto Brasileiro de Análises Sociais e Econômicas (IBASE), iniciativas lideradas pelo sociólogo Herbert de Souza (Betinho), contribuíram de forma significativa para a discussão sobre a Responsabilidade Social em nosso País. Outro marco fundamental para o cenário brasileiro foi a promulgação da Constituição Federal Brasileira, em 1988. Fica evidente no disposto pela Constituição Federal a relação estabelecida entre as questões ambientais e os direitos humanos, quando ela estabelece o "direito de todos a um meio ambiente ecologicamente sustentável." (BRASIL, 1988). Amorim (2009, p. 131) faz a seguinte reflexão:

Na comunidade empresarial, os gestores passaram também a ter a função ética de respeitar os direitos e promover o bem entre os agentes afetados pelas empresas que gerenciam. A sociedade também passou a ter mais consciência em relação à clara necessidade de o mundo praticar um desenvolvimento sustentável, tendo a capacidade de satisfazer as necessidades atuais das pessoas, sem comprometer as gerações futuras. Dessa forma, cada dia que passa, fica mais difícil às organizações, independentemente de porte e segmento, desconsiderarem a transparência, ética e responsabilidade socioambiental nos seus negócios. 
É na década de 1990 que tem origem o "conceito elaborado pelo World Council for Sustainable Development, segundo o qual a responsabilidade social empresarial faz parte do desenvolvimento sustentável.” (TENÓRIO et al., 2006, p. 25). Martins (2008) explica que o desenvolvimento sustentável implica uma visão diferenciada em relação ao crescimento econômico e ao progresso, outrora perseguido sem considerar os impactos que ele poderia causar. $\mathrm{Na}$ atualidade, tal conceito é compreendido como aquele que "Gera crescimento econômico, com crescimento da produção, da renda, do emprego e consequentemente de impostos pagos para que o governo ofereça os serviços públicos necessários a todos os cidadãos." (MARTINS, 2008, p. 20). Assim, segundo o autor:

A empresa preocupada com a sustentabilidade é a empresa que pratica a responsabilidade social e ambiental, mantendo uma postura ética e responsável com todos os seus públicos e, com isso, provando ser uma empresa que procura contribuir para o desenvolvimento sustentável. (MARTINS, 2008, p. 20).

Ganha tônica a ideia da Responsabilidade Social Ambiental, enfatizandose a interdependência entre o ser humano e o ambiente de forma a haver um desenvolvimento sustentável. Torres (2012, p. 20) destaca que a reflexão sobre a Responsabilidade Social "faz com que se pense globalmente. A sociedade está cada vez mais entrelaçada e conectada entre si, fazendo com que as ações locais repercutam de uma forma mais impactante e transformadora de valores." Diante disso,

Se for responsável social e ambientalmente, ou melhor, se for sustentável, a empresa tende a ser próspera e a ser vista como uma empresa cidadã, preocupada com os colaboradores, clientes, consumidores e corresponsável pelo desenvolvimento de sua comunidade e pelo futuro do planeta. Por outro lado, se não trilhar o caminho da sustentabilidade, a empresa pode desaparecer ou, no máximo, terá desempenhos tímidos, com pouca probabilidade de manutenção e muito menos de crescimento. (MARTINS, 2008, p. 9).

De forma resumida, Martins (2008, p. 18-19) indica que as organizações comprometidas com a Responsabilidade Social Ambiental se preocupam com os impactos de suas ações:

Nos colaboradores da empresa, o chamado público interno, que movimenta o dia a dia da organização. Nos fornecedores de matérias-primas e de vários tipos de insumos que ajudam a empresa a produzir e crescer. Nos clientes e consumidores, aqueles que adquirem os produtos e serviços oferecidos pela 
empresa. No meio ambiente, ou seja, a empresa tem muito cuidado na forma de lidar com a água, com a qualidade do ar, com a energia, com os dejetos que produz. Na comunidade, ou seja, a empresa está preocupada com o desenvolvimento do bairro, da cidade, onde está inserida. Na sociedade em geral e governo, ou seja, a empresa está muito atenta em cumprir as leis e ajudar no desenvolvimento do país.

Martins (2008, p. 15), ao definir a Responsabilidade Social, compreende tal conceito como sinônimo de outros conceitos relacionados a este, tal como apresentado a seguir:

\begin{abstract}
A Responsabilidade Social e Ambiental (RSA) empresarial ou corporativa pode ser descrita como nova forma de gerir e administrar os negócios, gerando mais valor para a empresa e os acionistas, e também para a sociedade em geral, a partir de postura ética, de cuidados, responsável com os diferentes públicos de relacionamento, com as redes em que essa empresa está inserida.
\end{abstract}

Com base no exposto, acerca da origem e evolução conceitual da Responsabilidade Social, podemos dizer, em termos de síntese, que ela "é a demonstração de preocupação da empresa em participar de forma ativa de programas sociais voltados para o bem-estar da comunidade na qual está inserida e da sociedade em geral.” (REETZ; TOTTOLA, 2006, p. 22).

Tenório et al. (2006) explicam que, na atualidade, o conceito de Responsabilidade Social sinaliza para três vertentes interpretativas. Numa visão mais simplificada "pode significar o cumprimento das obrigações legais e o comprometimento com o desenvolvimento econômico. Essa é uma abordagem industrial do conceito." (TENÓRIO et al., 2006, p. 31); numa compreensão mais ampla, compreende-se que a Responsabilidade Social vai além do cumprimento das questões legais e contempla “o envolvimento da empresa em atividades comunitárias.” (TENÓRIO, 2006, p. 31). Entretanto, essa segunda interpretação não é consensual entre os autores, segundo Tenório (2006, p. 31), pois alguns entendem que "o melhor significado para essa expressão seria cidadania empresarial.” A terceira interpretação corresponde à ideia de Responsabilidade Social Corporativa "como um compromisso da empresa com a sociedade na busca da melhoria da qualidade de vida da comunidade [...] uma série de compromissos da empresa com a sua cadeia produtiva: clientes, funcionários, fornecedores, comunidades, meio ambiente e sociedade.” (TENÓRIO, 2006, p. 31). 
Para Martins (2008), as discussões contemplando as questões da Responsabilidade Social e do desenvolvimento sustentável contribuíam tanto para o avanço conceitual a respeito desses dois termos quanto para a reflexão sobre os investimentos realizados pelas organizações, de forma que eles fossem aplicados de forma planejada, adequada e eficaz.

Assim, de forma ampla, o conceito da Responsabilidade Social diz respeito àquelas ações, posturas e comportamentos adotados por determinada organização, cuja principal finalidade é o compromisso com os impactos que o seu negócio pode causar na sociedade, primando pela minimização de tais impactos e a promoção do bem-estar da coletividade, seja no âmbito do público interno seja do externo a essa organização, visando ao desenvolvimento sustentável.

Conforme Amorim (2009, p. 138), “A organização preocupada em implantar uma cultura ética e de responsabilidade social deve definir princípios claros e simples para que todos entendam e assimilem.” Entre alguns princípios da Responsabilidade Social, destacam-se: accountability, transparência, comportamento ético, respeito pelos interesses das partes interessadas (stakeholders), respeito pelo Estado de Direito, respeito e observação das normas internacionais de comportamento, reconhecimento e respeito pela universalidade dos Direitos Humanos.

Estigara, Pereira e Lewis (2009, p. 18) evidenciam seis pilares da Responsabilidade Social, a saber: desenvolvimento, direitos humanos, proteção do consumidor, democracia e participação sociopolítica, ética na administração e governança e proteção do meio ambiente.

De acordo com os autores, tais pilares são os fundamentos da Responsabilidade Social. Os investimentos e os impactos das ações de Responsabilidade Social necessitam ser avaliados, e dessa forma é imprescindível a existência de indicadores que contribuam para tal aferição e de modos de socialização dos resultados, sendo o balanço social uma dessas possibilidades.

Tenório et al. (2006, p. 37) articulam o surgimento do Balanço Social “à crescente demanda, por parte da sociedade, de informações a respeito dos impactos que as atividades empresariais exercem sobre os trabalhadores, a sociedade, a comunidade e o meio ambiente." Para Ponchirolli (2009, p. 80-81), o Balanço Social

[...] se caracteriza pela demonstração das práticas de responsabilidade social, ou seja, por meio desse instrumento a empresa torna públicas as ações sociais que empreende com os seus diversos parceiros: empregados, comunidade, meio ambiente, 
entre outros. É um demonstrativo publicado anualmente pela empresa, reunindo um conjunto de informações sobre os projetos, benefícios e ações sociais dirigidas aos empregados, investidores, analistas de mercado, acionistas e à comunidade.

A partir dessa síntese relativa ao cenário evolutivo dos enfoques da RS, na próxima seção nos dedicamos à reflexão sobre a Responsabilidade Social nas Instituições de Ensino Superior, tendo como referência o estabelecido pelo Sistema Nacional de Avaliação da Educação Superior (SINAES).

\section{A RESPONSABILIDADE SOCIAL COMO INDICADOR DE QUALIDADE DA EDUCAÇÃO SUPERIOR: REFLEXÕES A PARTIR DO SISTEMA NACIONAL DE AVALIAÇÃO DA EDUCAÇÃO SUPERIOR (SINAES)}

A partir do SINAES, a Responsabilidade Social passa a ser uma exigência para todas as Instituições de Ensino Superior, públicas ou privadas (ASHLEY; FERREIRA; REIS, 2006), sendo ela referida como uma das finalidades desse Sistema de Avaliação:

O SINAES tem por finalidades a melhoria da qualidade da educação superior, a orientação da expansão da sua oferta, o aumento permanente da sua eficácia institucional e efetividade acadêmica e social e, especialmente, a promoção do aprofundamento dos compromissos e responsabilidades sociais das instituições de educação superior, por meio da valorização de sua missão pública, da promoção dos valores democráticos, do respeito à diferença e à diversidade, da afirmação da autonomia e da identidade institucional. (BRASIL, 2004, Art. $1^{\circ}, \S 1^{\circ}$, grifo nosso).

De acordo com o Instrumento de Avaliação dos Cursos de Graduação presencial e a distância, o indicador Responsabilidade Social é avaliado com base numa escala conceitual que varia de 1 a 5, sendo atribuído o conceito máximo (5)

Quando a responsabilidade social figura de modo explícito como diretriz relevante na missão social da IES no curso e está prevista/integrada, de maneira excelente, no cotidiano de sua gestão, considerando, em uma análise sistêmica e global, os seguintes aspectos: oportunidades para a comunidade acadêmica exercitar a responsabilidade social; existência de parcerias e contribuição para a concepção, planejamento e execução das atividades educacionais. (BRASIL, 2016, p. 23). 
Entendemos que a descrição do indicador apresentada não oferece elementos suficientes para as IES delinearem suas ações de responsabilidade social e respectiva abrangência, e nem para mensurar os impactos causados por elas, tanto no âmbito da própria instituição quanto para o público externo. Dito de outra forma, não fica evidenciada a ideia do engajamento efetivo e o papel das IES na formação de um profissional cidadão comprometido com a consolidação de uma sociedade mais justa, solidária e igualitária, pautada por um desenvolvimento sustentável. Muito mais que promover ou possibilitar oportunidades para a comunidade acadêmica exercitar a responsabilidade social, sob a perspectiva de projetos ou outras ações, parecenos que o elemento central nessa discussão acerca da RS é a formação das pessoas. Corroboramos a posição de Dias Sobrinho (2005, p. 171):

É preciso que a formação das pessoas tenha como valor mais alto a cidadania. Isso significa, num primeiro ponto de vista, que deve haver um incremento ético a contrapor-se às assimetrias geradas nas esferas econômica, social e cultural; que deve ser promovida a socialidade, na qual hoje impera o individualismo; que devem ser priorizados o espaço público e os processos de autonomia e vitalização das relações interpessoais, em vez da autorreferenciação mercantilista. Isso afirma também o valor da integração construtiva na vida democrática, regida por leis e projetos de interesse geral e assegurada pelo exercício da cidadania pública que sustenta as instituições sociais. Significa ainda que, para além da autonomia privada, a cada um confere o direito de viver livremente dentro dos limites legais, e é preciso que a educação reinstaure o sentido da participação política, ou seja, da autonomia cívica.

Outro desafio está no fato de que, conforme assinala Dias Sobrinho (2005, p. 164), “os problemas sociais não são nada precisos; em consequência, as demandas à educação também não estão bem definidas e tampouco há clareza quanto ao que seriam respostas adequadas." Continua o autor destacando que:

Embora não de modo absolutamente consensual, predominam hoje os julgamentos de que a universidade deve motorizar as transformações exigidas pela nova economia de mercado. Mas também cabe à universidade - e esta é uma bandeira histórica, essencial e indescartável - elaborar uma compreensão ampla e fundamentada relativamente às finalidades e transformações da sociedade. É bem verdade que muitos dos problemas são comuns tanto à universidade em particular quanto à sociedade em geral. Porém, se a universidade não toma distância crítica para melhor ver a sociedade, ela se perde, e, então, perde a sociedade sua mais legítima instância de reflexão e de síntese. Se a universidade adere acriticamente aos "objetivos" da sociedade, 
hoje mais identificados com a orientação tecnocrática e gestionária, ela abdica de sua função de formação, de educação e de autonomização dos sujeitos, em favor da organização da produção e de um pretendido controle das relações entre indivíduos. Quando obsessivos e reduzidos a uma mera dimensão econômica e pragmática, os fetichismos da máxima proficiência, da produtividade, da excelência, e a compulsão pelo conhecimento de pronta aplicação constituem uma ameaça à construção histórica da universidade crítica. A desfiguração da universidade não vitima somente a ela; tem como consequência o empobrecimento da própria sociedade, pois esta se desprovê de sua principal instância reflexiva, cultural e civilizacional. Não perder sua vocação crítica e sua capacidade de visão de conjunto é muito importante para a universidade. Mas isso não significa autorreferenciação. A universidade faz parte da totalidade da vida social. (DIAS SOBRINHO, 2005, p. 165, grifo do autor).

\section{É fundamental assinalar o caráter público e social das Instituições de}

Ensino Superior, independentemente de quem é responsável por sua administração e manutenção. Portanto, articuladas à formação técnica do profissional, as IES também possuem o papel de formar, moral e intelectualmente, as pessoas. Assim, no entender de Dias Sobrinho (2005, p. 170):

Essa função pública é a sua responsabilidade social. Então, é sumamente importante que a educação superior produza conhecimentos e formação com um grande sentido de pertinência social. Por meio do conhecimento e do trabalho de formação, sem abdicar de suas competências críticas, ela deve desenvolver a capacidade de resposta às demandas e às carências da sociedade. A pertinência requer autonomia para identificar as prioridades e o conteúdo social das carências e demandas. Isso exige uma ampla participação de estudantes, professores e pesquisadores na definição de prioridades sociais e na produção e socialização do conhecimento rigoroso e adequado. Em outras palavras, é preciso instaurar uma ética da responsabilidade social que vincule os atores acadêmicos e os agentes da sociedade civil organizada às agendas públicas realmente voltadas ao atendimento das demandas das populações, e não à legitimação do mercantilismo da globalização neoliberal.

Portanto, conclui o autor:

[...] a responsabilidade social da educação superior deve significar relevância científica e pertinência, fortalecimento da vida democrática e da justiça social, aprofundamento da ética e do sentido estético da sociedade. O sentido essencial da responsabilidade social da educação superior consiste em produzir e socializar conhecimentos que tenham não só mérito científico, mas também valor social e formativo. Portanto, que sejam im- 
portantes para o desenvolvimento econômico e que tenham sentido de cidadania pública. (DIAS SOBRINHO, 2005, p. 172).

Também Gómez Restrepo (2010, p. 20, grifo do autor) reafirma o papel formador das IES:

[...] la universidad es, primordialmente, formadora de personas y generadora de conocimiento más que productora de bienes o proveedora de servicios. Desde tal virtud, el mundo de hoy nos exige no solamente formar buenos profesionales, si por ello hemos de entender que sean competentes y éticamente responsables. Implica, además, que sean sensibles a los problemas sociales, respetuosos de la dignidad humana, defensores de la justicia y la equidad, comprometidos con el medio ambiente, creativos en la búsqueda de soluciones a la complejidad del presente, y partícipes de los procesos políticos $y$ democráticos de sus países y comunidades. Esto nos vincula a la dinámica social, es decir, nos hace 'pertinentes'. Y sin embargo, más que pertinente - si por ello hemos de entender el alineamiento con lo políticamente correcto y con la satisfacción de las expectativas que los gobiernos o la mayor parte de los grupos sociales tienen frente a la universidad-, quizás se podría decir que gran parte de la pertinencia de la universidad es, precisamente, ser impertinente. No de otra manera podría ser parte de la conciencia moral de un país ni podría ser el lugar donde la crítica, la propuesta, el examen de lo comúnmente aceptado, el pensamiento novedoso, la alternativa pueda tener lugar. La universidad, por lo tanto, es también - al menos en la mayoría de ellas - el lugar de los jóvenes y de los académicos, del diálogo posible de las nuevas generaciones que buscan el conocimiento y de los profesores e investigadores que se ocupan de él, no como dispensadores sino como generadores, no como los que enseñan sino como quienes crean las condiciones para que aprender sea posible.

Conforme destacamos na introdução, o conceito de Responsabilidade Social não deve ser confundido com o de filantropia ou de ações assistenciais, pois ela é

[...] fundamentalmente, una manera de posicionarse en la sociedad en que se encuentra porque su acción tiene impactos de diversos tipos. Impactos fruto de la formación que imparte: esto significa la vivencia y aprendizaje de valores, de principios, de una ética que permee la vida de profesores y estudiantes y que les permita actuar responsablemente en el ejercicio de sus profesiones. Impactos fruto de la investigación que implementa y el conocimiento que genera, lo cual significa preguntarse ¿qué tipo de conocimiento y proyectos vamos a realizar y para responder a qué tipo de preguntas o problemas? Impactos de orden político, porque hace parte de la conciencia moral de la nación, esto es, cuál es la opinión de la universidad en 
ciertos temas sensibles para el fortalecimiento del tejido social, además que es su obligación participar en el debate público y en la construcción de políticas públicas de temas que la atañen porque en su seno hay gente capaz de aportar en muchos temas. Impactos de orden financiero, por cuanto la universidad, asi sea de gestión privada, suele manejar recursos públicos procedentes de grants o de convocatorias públicas para proyectos de investigación. Impactos porque en su función democratizadora, la universidad tiene que examinar cuidadosamente las implicaciones éticas que conllevan los proyectos de investigación e intervención; esto hace que la universidad propicie el entendimiento de la ciencia por el gran público al tiempo que abra el debate para opinar y convocar en torno a los temas cientificos. (GÓMEZ RESTREPO, 2010, p. 47-48, grifo do autor).

Apesar de o SINAES não aprofundar o conceito de Responsabilidade Social Universitária, é possível constatar um acento na superação de uma visão meramente assistencialista em termos de projetos sociais.

Autores como Jiménez de La Jara, Fontecilla e Troncoso (2006), Vallayes (2006), Calderón $(2005,2008)$ e Calderón, Pedro e Vargas (2011) trazem contribuições significativas para o avanço nas discussões acerca da Responsabilidade Social nas Instituições de Ensino Superior. Para Vallayes (2006, p. 39):

A Responsabilidade Social Universitária exige, a partir de uma visão holística, a articulação dos diversos setores da instituição, em um projeto de promoção social de princípios éticos e de desenvolvimento social equitativo e sustentável, com vistas à produção e transmissão de saberes responsável e à formação de profissionais cidadãos igualmente responsáveis.

Jiménez de La Jara, Fontecilla e Troncoso (2006, p. 63) destacam que a Responsabilidade Social é a

capacidade que possui a universidade de difundir e colocar em prática um conjunto de princípios e valores, gerais e específicos, por meio de quatro processos considerados chaves: gestão, docência, pesquisa e extensão universitária, respondendo socialmente desta forma perante a própria comunidade universitária e o país onde está inserida.

Jiménez de La Jara, Fontecilla e Troncoso (2006) consideram como processos-chaves na universidade a docência, a gestão, a pesquisa e a extensão. Com isso, as discussões a respeito da Responsabilidade Social (a exemplo daquelas no campo empresarial), numa visão sistêmica, ultrapassam os modos de relação com a sociedade e se voltam também para as questões dos processos e práticas de gestão, relação com os 
colaboradores, organização curricular, formação discente, entre outras. A visão desses autores acrescenta um componente fundamental para a execução da Responsabilidade Social, que os autores chamam de elemento-chave, que é a gestão, contribuição que deve se consolidar a partir da definição de mecanismos administrativos que viabilizem a Responsabilidade Social nas IES. Nesse sentido, perpassa pela postura e pelo modelo de gestão das IES o desejo executivo de direcionar as atividades institucionais de ensino, pesquisa e extensão para atender ao pressuposto transversal da Responsabilidade Social nas ações e processos de interação com a sociedade.

Vallaeys (2006) defende uma nova dinâmica universitária, permeando três fatores - a garantia da Responsabilidade Social da ciência, a promoção da formação cidadã democrática e a formação calcada nos fundamentos da formação transversal de agentes para o desenvolvimento. Esse viés formativo deve ser disseminado por meio do ensino, da pesquisa e da extensão, elementos tradicionais e basilares das universidades que, segundo Vallaeys (2006, p. 45), permitem a "construção das pontes entre a universidade e a sociedade, a concretização do compromisso social da universidade e a reflexão ética sobre a dimensão social do ensino e da pesquisa, e têm sido uma atribuição da chamada extensão universitária."

Assim, para a efetivação das ações de RS, a área da extensão é compreendida como um lócus privilegiado, não se confundindo com a Responsabilidade Social propriamente dita, como esclarecem Calderón, Pedro e Vargas (2011, p. 1187):

Este fato gerou, inicialmente, certa confusão teórica entre o que seria a Responsabilidade Social da Educação Superior e a chamada extensão universitária. Trata-se de um impasse teórico que foi paulatinamente superado, na medida em que o conceito de RSES e o de compromisso social foram vinculados às discussões sobre a função social das IES. Por sua vez, a extensão universitária foi identificada como uma das três atividades universitárias, juntamente com o ensino e a pesquisa, que possibilitam que as IES cumpram sua responsabilidade social.

Diante da existência de um indicador direcionado à aferição da RS dentro do SINAES, as IES são mobilizadas a refletir sobre os investimentos e recursos necessários a serem direcionados para tais ações e de que forma tais ações impactam no negócio e na missão institucional. Além dos impactos na própria IES, também os impactos causados pelas ações de RS em termos de intervenção e transformação social. Aqui reside um dos desafios às IES, considerando, conforme exposto, que no SINAES a forma de avaliação do indicador RS é muito ampla. 


\section{CONSIDERAÇÕES FINAIS}

Com base na revisão de literatura realizada, os achados do estudo sinalizam a Responsabilidade Social como um componente essencial no processo formativo dos acadêmicos; o cumprimento da tríplice missão universitária do ensino, da pesquisa e da extensão; e a efetivação da própria função social das Instituições de Ensino Superior.

A Responsabilidade Social nas IES não deve ser confundida com ações de assistencialismo, voluntariado ou filantropia e, tampouco, com ações de cunho extensionista. A Responsabilidade Social diz respeito à própria identidade e à função social das IES. Dessa forma, a efetivação da função social das Instituições de Ensino Superior se materializa por meio da educação, que é a finalidade e razão da existência dessas instituições (DURHAM, 2005). Por isso, a Responsabilidade Social está diretamente relacionada ao modus operandi de uma IES, contemplando desde as práticas de gestão até o projeto educativo que pauta suas ações em termos de formação pessoal, técnica e científica, a qual não pode estar dissociada da formação cidadã do futuro profissional. Desse ponto de vista, o compromisso social faz parte da identidade institucional, mobilizando e retroalimentando os saberes e fazeres da comunidade acadêmica, na busca conjunta por possíveis soluções para os problemas encontrados numa relação dialógica.

\section{REFERÊNCIAS}

AMORIM, T. N. G. F. Responsabilidade Social Corporativa. In: ALBUQUERQUE, J. de L. (Org.). Gestão Ambiental e Responsabilidade Social: conceito, ferramentas e aplicações. São Paulo: Editora Atlas, 2009, p. 130-173.

ASHLEY, P.; FERREIRA, R.; REIS, H. Sistema Nacional de Avaliação da Educação Superior: Oportunidades para a responsabilidade social na gestão estratégica de instituições de ensino superior. Revistas Gerenciais, São Paulo, v. 5, p. 23-35, 2006.

BRASIL. Constituição. República Federativa do Brasil de 1988. Brasília, DF: Senado Federal, 05 out. 1988. Disponível em: <http://www.planalto.gov.br/ccivil_03/ Constituicao/Constituicao.htm>. Acesso em out. 2014.

BRASIL. Lei n. 10.861, de 14 de abril de 2004. Institui o Sistema Nacional de Avaliação da Educação Superior (SINAES) e dá outras providências. Diário Oficial da União, Brasília, DF, 15 abr. 2004. 
BRASIL. Ministério da Educação (MEC). Instituto Nacional de Estudos e Pesquisas Educacionais Anísio Teixeira (INEP). Diretoria de Avaliação de Educação Superior (DAES). Coordenação-geral de Avaliação de Cursos de Graduação e Instituições de Ensino Superior (CGACGIES). Nota Técnica No 14 /2014 - CGACGIES/DAES/ INEP/MEC. Brasília, DF, 2014.

BRASIL. Ministério da Educação (MEC). Instituto Nacional de Estudos e Pesquisas Educacionais Anísio Teixeira (INEP). Diretoria de Avaliação de Educação Superior (DAES). Sistema Nacional de Avaliação da Educação Superior (SINAES). Instrumento de Avaliação dos Cursos de Graduação presencial e a distância. Brasília, DF, 2016.

CALDERÓN, A. I. Responsabilidade Social: desafios à gestão universitária. Estudos, v. 22, n. 34, p. 13-27, 2005.

CALDERÓN, A. I. Responsabilidade social da educação superior: da tradição universitária à estratégia de marketing e normatização estatal. Diálogos, v. 9, p. 45-50, 2008.

CALDERÓN, A. I.; PEDRO, R. F.; VARGAS, M. C. Responsabilidade Social da Educação Superior: a metamorfose do discurso da UNESCO em foco. Interface Comunicação, Saúde, Educação, v. 15, n. 39, p. 1185-1198, out./dez. 2011.

DAHER, W. de M. Responsabilidade Social Corporativa: geração de valor reputacional nas organizações internacionalizadas. São Paulo: Saint Paul, 2006.

DIAS SOBRINHO, J. D. Educação superior, globalização e democratização. Qual universidade? Revista Brasileira de Educação, n. 28, p. 164-173, 2005.

DOURADO, L. F.; OLIVEIRA, J. F. A qualidade da Educação: Perspectivas e desafios. Caderno Cedes, Campinas v. 29, n. 78, p. 201-215, maio/ago. 2009.

DOURADO, L. F.; OLIVEIRA, J. F., SANTOS, C. de A. A qualidade da Educação: conceitos e definições. Série Documental: Textos para Discussão. Brasília, DF, v. 24, n. 22, p. 5-34, 2007.

DURHAM, E. A responsabilidade social das instituições de ensino superior. Estudos, v. 22, n. 34, p. 13-27, 2005.

ESTIGARA, A.; PEREIRA, R.; LEWIS, S. A. L. B. Responsabilidade Social e Incentivos Fiscais. São Paulo: Atlas, 2009. 
GÓMEZ RESTREPO, C. G. La responsabilidad social de la universidad lasallista: elementos para la reflexión y el debate. Revista de La Universidad De La Salle, n. 51, p. 15-53, 2010.

JIMÉNEZ DE LA JARA, M.; FONTECILLA, J. M.; TRONCOSO, C. D. Responsabilidade universitária: uma experiência inovadora na América Latina. Estudos, v. 24, n. 36, p. 57-73, 2006.

MARTINS, J. P. S. Responsabilidade Social Corporativa: como a postura responsável compartilhada pode gerar valor. Campinas: Komedi, 2008.

ORGANIZAÇÃO DAS NAÇÕES UNIDAS -ONU. Declaração Universal dos

Direitos Humanos. 1948. Disponível em: <http:/www.onu-brasil.org.br/documentos_direitos humanos.php>.Acesso em: 22 jan. 2017.

PONCHIROLLI, O. Ética e responsabilidade social empresarial. 1. ed. Curitiba: Juruá, 2009.

REETZ, L.; TOTTOLA, E. de C. Responsabilidade Social: impossível ficar de fora. São Paulo: LivroPronto, 2006.

ROESCH, S. M. A. Projetos de Estágio e de Pesquisa em Administração. 3. ed. São Paulo, Editorial Atlas, 2010.

TAWIL, S.; AKKARI, A.; MACEDO, B. Más allá del labirinto conceptual - La noción de la calidad en la educación. Investigación y prospectiva en educación. Unesco: Contribuciones Temáticas - n. 2. UNESCO, Marzo, 2012.

TENÓRIO, F. G. et al. Responsabilidade social empresarial: teoria e prática. 2. ed. Rio de Janeiro: Editora FGV, 2006.

TORRES, L. E. S. Proposta de modelo de gestão universitária baseado em sustentabilidade: aplicação ao caso PUC-Rio. 2012. 67 p. Dissertação (Mestrado em Engenharia de Produção)-Pontifícia Universidade Católica do Rio de Janeiro, Rio de Janeiro, 2012.

VALLAEYS, F. O que significa responsabilidade social universitária? Estudos, v. 24, n. 36, p. 35-56, 2006.

Recebido em: 08 de agosto de 2017

Aceito em: 26 de janeiro de 2018

Endereço para correspondência: Rua Gastão Gonçalves, 79, Bairro Santa Rosa, 24240-030, Niterói, Rio de Janeiro, Brasil; jardelino.menegat@lasalle.org.br 
